\title{
A Dificuldade do Texto Lacaniano
}

\author{
Flávio Fernandes Fontes" \& Cynthia Pereira de Medeiros ${ }^{* *}$ \\ Universidade Federal do Rio Grande do Norte, Natal, Brasil
}

\begin{abstract}
RESUMO
Procurando compreender a dificuldade do texto lacaniano, levantamos, a partir de um estudo teórico, as interpretações dadas tanto por autores que abordam o tema do estilo de Lacan sob uma perspectiva crítica, quanto por aqueles que o justificam e defendem sua legitimidade, utilizando também algumas obras do próprio Lacan. A análise do trabalho desses comentadores nos levou a oito explicações diferentes para o estilo lacaniano. Ressalta-se o debate entre a corrente científica, que exige clareza e condena as características desse estilo como impróprias para um discurso científico, e a corrente subjetiva, que o justifica como um modo intencional e particular de transmissão da psicanálise.
\end{abstract}

Palavras-chave: Lacan; estilo; crítica; psicanálise; transmissão.

\begin{abstract}
The Difficulty of the Lacanian Text

Trying to comprehend the difficulty of the Lacanian text through a theoretical study, we compiled interpretations by commentators that address the subject of the Lacanian style from a critical perspective and from those who justify and defend its legitimacy, using also some of Lacan's own work. The analysis of these commentators's work has driven us to list eight different explanations to the Lacanian style. It is emphasized the importance of the debate between the scientific current, that demands clarity and condemns the characteristics of the Lacanian style as inadequate to a scientific discourse, and the subjective current, that justifies it as an intentional and particular way of transmitting psychoanalysis.
\end{abstract}

Keywords: Lacan; style; criticism; psychoanalysis; transmission.

"Temos bastante orgulho, saiba-se disso, deste poder de ileitura que soubemos manter intacto em nossos textos." (Lacan, 1969/2003, p. 379)

Esse artigo nasceu da curiosidade, do desejo de saber, do questionamento, enfim, que é provocado pelos escritos de Jacques Lacan. Suscitar o desejo parece ter sido uma das principais marcas do famoso e controverso psicanalista francês, uma vez que seus seminários atraiam um grande número de ouvintes que se interessavam pelo que ele tinha a dizer, nem sempre psicanalistas, mas muitas vezes oriundos de outros campos do saber. Seu discurso provocou a fundação de inúmeros grupos e instituições psicanalíticas em várias partes do mundo, e continua a inspirar pesqui$\operatorname{sas}^{1}$, teses e eventos em que suas ideias são utilizadas e discutidas.
Levando em conta as dificuldades que existem em entender Lacan é notória a quantidade de obras que se propõem a explicá-lo. Para Compreender Lacan (Fages, 1975), Lacan Elucidado (Miller, 1997), O Ensino de Lacan (Mendonça, 1993), Lacan: Operadores da Leitura (Vallejo e Magalhães, 1981), Introdução à Leitura de Lacan (Dor, 1992), How to Read Lacan (Zizek, 2007), Curso e Discurso da Obra de Jacques Lacan (Cabas, 1982), etc. Os títulos se avolumam, a ponto de Cesarotto e Leite (1993) escreverem um capítulo de "introdução às introduções".

Como compreender tal estilo enigmático e polêmico de expressão? Com o objetivo de responder tal questão, levantamos quais as interpretações dadas pelos comentadores a partir de um estudo teórico, levando em conta tanto os autores que abordaram o tema do estilo de Lacan sob uma perspectiva crítica,

\footnotetext{
* Endereço para correspondência: Flávio Fernandes Fontes: flavioffontes@ hotmail.com

** Endereço para correspondência: Cynthia Pereira de Medeiros: cynthiamedeiros@yahoo.com
} 
como Beividas (2000) e Sokal e Bricmont (1999), como aqueles que o justificam e defendem sua legitimidade, a exemplo de Glynos e Stavrakakis (2001), Fink (1997) e Souza (1985), utilizando também algumas obras do próprio Lacan.

Se percebemos Lacan como um mistério a ser desvendado, é porque reconhecemos que algo não está claro, que sua palavra constitui um problema em que o obscuro e o insondável tomam parte. "Lacan é difícil de ler, sem dúvida nenhuma. Sobre isso, pelo menos, simpatizantes e detratores de Lacan estão de acordo" (Glynos \& Stavrakakis, 2001). Ao contrário do que pode parecer à primeira vista, essa dificuldade não é fruto de traduções deficientes de sua obra, da diferença cultural que nos separa - leitores brasileiros - do contexto francês, nem da falta de erudição ou do despreparo típico do estudante iniciante. Para justificar essa afirmação, basta apontar que Lévi-Strauss (19082009) afirmou expressamente que não o compreendia, Paul Ricoeur (1913-2005) achava impenetrável o que ele dizia, e J. Hyppolite (1907-1968) disse ser levado à tortura pelas aporias que a linguagem de Lacan provoca, nunca estando bastante seguro de o compreen$\operatorname{der}^{2}$ (Beividas, 2000).

Ricoeur e Hyppolite são franceses, e Lévi-Strauss belga, porém todos os três tiveram uma história de vida profundamente ligada à academia francesa e à França em geral. Ricoeur estudou na universidade de Rennes e na Sorbonne, e ensinou na universidade de Estrasburgo, além de ter servido ao exército francês na segunda guerra mundial. Hyppolite frequentou o curso de Kojève sobre Hegel (curso este que tanto influenciaria a Lacan), ensinou em Estrasburgo e Sorbonne e foi diretor da École Normale Supérieure. Lévi-Strauss foi professor de antropologia estrutural no Collège de France de Paris durante vinte anos. Somando a isso o fato de pertencerem à mesma geração que Lacan, não podemos dizer que tais pessoas estariam culturalmente, linguisticamente ou intelectualmente despreparadas para entender o que ele dizia.

É preciso apontar que tal estilo que poderíamos qualificar de hermético é assumido de forma explícita e proposital por Lacan em vários momentos além do já citado na epígrafe deste artigo, como, por exemplo:

Um escrito, em minha opinião, é feito para não se ler. (Lacan, 1973/2003, p. 503)

Não penso entregar-lhes meu ensino sob a forma de um comprimido. (Lacan, 1967/2006, p. 11)
E também em "A instância da letra no inconsciente ou a razão desde Freud” (1957/1998):

$\mathrm{O}$ escrito distingue-se, com efeito, por uma prevalência do texto (...) o que permite a concisão que, a meu ver, não deve deixar ao leitor outra saída senão a entrada nele, que prefiro difícil. (p. 496)

De fato, Lacan chegou a expressar que se poderia considerar os seus Escritos um livro ilegível, dado que "muito grande, difícil de ler, obscuro" (2006, p. 72). Assim, estabelecemos como primeiro ponto o fato de que a dificuldade do texto de Lacan não é acidental, mas sim um dado objetivo e proposital, que tem uma intenção declarada: levar o leitor a dar algo de si, tal como é afirmado na abertura dos Escritos (Lacan, 1966/1998, p. 11).

Passaremos a examinar agora algumas interpretações dadas por comentadores a essa estratégia, incluindo opiniões contrárias, favoráveis ou meramente descritivas. Chomsky (1989, citado por Hanlon, 2001) chegou a afirmar em uma entrevista: "Minha sincera opinião é que Lacan era um charlatão consciente, e que ele estava simplesmente brincando com a comunidade intelectual de Paris para ver quantos absurdos ele poderia produzir e ainda assim ser levado a sério"3. Sob essa ótica, a dificuldade seria apenas um véu para impressionar e fascinar a audiência, que, por medo de se passar por não-inteligente, fingiria ver sentido em suas afirmações e matemas. Seria um recurso para intimidar questionamentos e esconder o fato de que muitas afirmações simplesmente não faziam sentido.

Nessa mesma direção, Hanlon (2001), por sua vez, aponta que "Lacan, assim dizem seus detratores, fez uma carreira do obscurantismo, e talvez não tenha sequer acreditado em muito do que disse" ${ }^{4}$. Esses julgamentos são particularmente interessantes por darem voz à impressão que Lacan causa nos leitores que o repudiam.

Impressão que é assim retratada por Fink (1998):

A reação nos Estados Unidos para com um autor como Lacan é: 1. Se não consigo entendê-lo, então não vale a pena pensar a respeito dele. 2 . Se ele não consegue se expressar claramente, então seu pensamento deve ser confuso. 3. Nunca dei muito valor à teoria francesa de qualquer forma. (p. 185)

Mas tais julgamentos também receberam um tratamento melhor elaborado no polêmico livro de Sokal e Bricmont (1999), livro que trata da "mistificação, da linguagem deliberadamente obscura, dos pensamentos confusos e do emprego incorreto dos conceitos cientí- 
ficos" (p. 11). Para esses autores, se trata de mostrar que o rei está nu, que os textos não são difíceis por serem extremamente profundos e complicados, mas sim porque não querem dizer nada. A argumentação é baseada sempre em passagens específicas que servem de exemplo para o que está sendo criticado. Acusações bem fundamentadas são feitas no sentido de que Lacan manipularia frases e sentenças que seriam em última instância sem sentido, e utilizaria conceitos provenientes de outras ciências sem justificativa razoável, como forma de impressionar e mostrar erudição, intimidando os leitores.

Por fim, é considerado:

Os defensores de Lacan (bem como de outros autores aqui discutidos) inclinam-se a responder a essas críticas recorrendo a uma estratégia que iremos chamar de 'nem/nem': esses textos não devem ser avaliados nem como ciência, nem como filosofia, nem como poesia, nem... Fica-se então diante daquilo que se poderia chamar um 'misticismo laico': misticismo, porque o discurso objetiva provocar efeitos mentais que não são puramente estéticos, e sem se direcionar, de modo algum, à razão; laico, porque as referências culturais (Kant, Hegel, Marx, Freud, matemática, literatura contemporânea...) nada têm a ver com as religiões tradicionais e são atraentes ao leitor moderno. Além do mais, os textos de Lacan tornaram-se com o tempo cada vez mais enigmáticos - característica comum a muitos textos sagrados -, combinando jogos de palavras com sintaxe fraturada; e eles serviram de base para a exegese reverencial de que se incumbiriam seus discípulos. Podemos perguntar se não estamos, afinal de contas, lidando com uma nova religião. (Sokal \& Bricmont, 1999, pp. 47-48)

Sokal e Bricmont alertam com veemência para os perigos da falta de sentido e razão nos textos, bem como para os fins de mistificação desse procedimento, que levam o grupo a ser comparado a uma religião ${ }^{5}$. O livro esclarece ainda por mostrar Lacan, dentro do contexto francês da época, que é caracterizado como sendo abundante em exemplos de autores com escritas enigmáticas, verborrágicas e cheias de referências a conceitos das ciências naturais de forma bizarra e desorganizada. As análises feitas de autores como Julia Kristeva, Luce Irigaray, Jean Baudrillard, Gilles Deleuze, Félix Guattari e Paul Virilio demonstram isso (Sokal \& Bricmont, 1999).

Acrescentaríamos que, mesmo em autores como Lévi-Strauss, Michel Foucault, Louis Althusser e Roland Barthes, o papel destacado do estilo de escrita é algo que se sobressai em suas obras, embora com uma intensidade e um peso diferente para cada um: "Seja em Lacan ou Lévi-Strauss, em Barthes ou Foucault, existe, nos escritos da França do pós-guerra, uma qualidade poética inconfundível, um desejo de criar mitos e ficções" (Schneiderman, 1988, p. 148).

Em um ótimo livro para entender melhor a tendência cultural francesa dessa época, Merquior (1991) afirma que o estruturalismo formado por esses autores e Lacan não foi um movimento unificado, nem muito menos uma escola, mas sim um estilo de pensamento no lado humanístico do conhecimento. Um estilo colonizado pela influência do modernismo na literatura e na arte, e que promoveu uma "literarização do pensamento", que acabaria desembocando no pós-estruturalismo desconstrutivista de Derrida. Insistimos nisso para mostrar que o estilo Lacaniano não é algo proveniente somente do singular sujeito Lacan, mas tem fortes componentes de consonância com o momento vivido pela cultura francesa.

No entanto, a publicação de Sokal e Bricmont não foi recebida sem discussão e crítica. Em um artigo de resposta aos ataques feitos a Lacan nesse livro, Glynos e Stavrakakis (2001) defendem o estilo antipedagógico do psicanalista francês, enxergam a utilidade e a função do seu estilo de linguagem e o consideram justificado pelo objetivo de provocar uma postura ativa no público. Como o título do artigo desses autores mostra, não se trataria de uma impostura intelectual, mas sim de uma postura diferente daquela exigida pelo ponto de vista científico de Sokal e Bricmont (1999). Assim, a posição de Lacan é lida como deliberadamente crítica do discurso pedagógico, e por isso age de forma a questioná-lo e subvertê-lo. Fazer com que o leitor dê algo de si na construção do sentido do texto, em vez de esperar recebê-lo já pronto seria um modo de fazer da leitura um processo muito mais exigente e estimulante, tornando o leitor um decifrador, co-criador (Glynos \& Stavrakakis, 2001; Souza, 1985).

Assim, na medida em que utiliza uma margem proposital de sem-sentido, de não compreensão, o texto lacaniano provoca um desejo de saber, que acaba resultando em produção de sentido e de pesquisa, implicando o sujeito em um percurso de questionamento, de busca e desenvolvimento de respostas, pelo qual ele deve se responsabilizar. Essa interessante passagem de Fink (1997) atinge a essência dessa compreensão de Lacan, ao dizer:

Ele [Lacan] procura obter certos efeitos no leitor que não sejam efeitos de significado: ele procura nos despertar, nos provocar, nos perturbar - não nos em- 
balar e sim nos sacudir para fora de nossas rotinas conceptuais. Consequientemente, sua intenção é nos fazer trabalhar, nos lembrar que não compreendemos o que pensamos que compreendemos (sejam os textos de Freud que dão a ilusão de serem fáceis, ou os discursos de nosso analisando), e que talvez tenhamos que fazer várias tentativas para expressar ou conceituar algo, e mesmo assim nossa interpretação será apenas aproximadamente correta: ainda assim erraremos o alvo. (p. 220) ${ }^{6}$

A distinção feita por Barthes (1975, citado por Merquior, 1991) entre textos legíveis e "escrevíveis" pode ser útil para fundamentar ainda mais essa concepção do estilo de Lacan, que é basicamente concordante com a intenção declarada na abertura dos Escritos. Para Barthes, nos textos legíveis pode-se ir dos significantes aos significados de forma direta e automática, pois esses textos predeterminam seu significado, cabendo ao leitor apenas a liberdade de aceitar ou recusar o que é dito. Já os textos "escrevíveis" demandam um leitor ativo, transformado em coautor virtual, pois seu jogo de significantes adia indefinidamente o significado, que é eminentemente plural. Segundo essa teoria, Lacan seria interpretado como um praticante de textos "escrevíveis".

Para Fink (2004), escrever difícil foi a maneira que Lacan escolheu para evitar que seu texto fosse facilmente distorcido, tal como ele acreditava que a psicologia do ego americana havia distorcido Freud. "[Lacan] parece ter se dado a grandes trabalhos para impedir que as pessoas descobrissem o que tinha a dizer" diz Schneiderman (1988, p. 7), o que corrobora a percepção de Roudinesco (2008): "Da mesma forma que temia o plágio, Lacan buscava conservar secretas suas belas idéias... esse homem genial manifestava uma espécie de terror à idéia de que sua obra pudesse escapar à interpretação que ele próprio queria lhe dar" (p. 435).

Souza (1985) observa que essa excentricidade lacaniana impede que se possa "lhe atribuir um sentido que obture e estabeleça um quadro referencial estático" (p. 30-31) - trata-se de uma verdadeira recusa de ser identificado de maneira simplista e classificatória pelo outro. O seu estilo camaleônico pode ser visto como uma defesa contra o que os outros fariam de seu pensamento, tentando preservá-lo em sua originalidade e complexidade, ou ao menos dificultar o acesso o máximo possível, adiando o momento de deturpação inevitável com seus jogos de equívocos e ocultamentos.

Uma outra compreensão do estilo de Lacan dada por Fink (2004), é que Lacan situa seu discurso como um discurso de analisando, e o faz de propósito, de forma a treinar os analistas no processo de decifração:

Em sua escrita nós testemunhamos um verdadeiro dilúvio de polissemia, duplos sentidos, triplos sentidos, equívocos, enigmas, chistes e assim por diante. Seus textos e seminários parecem feitos para nos introduzir no tipo de trabalho que uma análise propriamente requer, examinando cuidadosamente camadas de sentido, decifrando o texto como se ele fosse uma longa série de lapsos de linguagem. Ele diz em um dado momento que seu estilo de escrita é deliberadamente projetado para contribuir para o treinamento de analistas ('toda minha retórica visa contribuir para o efeito de treinamento' [E 722]). ${ }^{7}$ (Fink, 2004, p. 155. Ver também p. 69 e p. 70.)

Em um sentido parecido, podemos também citar Alves $^{8}$ (1992):

Com seus escritos, Lacan ensina-nos a proceder com o saber textual, isto obrigando à mesma leitura que o inconsciente. Longe de um livre-arbítrio, aqui mais que nunca, devemos seguir as leis da decifração: no retorno de certas palavras, certas conexões. No nível do significante, não no da significação. (p. 75)

\section{E também Althusser (1964/1991):}

Tendo de ensinar a teoria do inconsciente a médicos, analistas ou analisandos, Lacan lhes dá, na retórica de sua palavra, o equivalente em mímica da linguagem do inconsciente, que é, como todos sabem, em sua essência última, 'Witz', trocadilho, metáfora, fracassada ou bem sucedida: o equivalente da experiência vivida em sua prática, seja ela de analista ou de analisando. (p. 59)

A relevância dessa interpretação é confirmada pelo seguinte trecho de Lacan (1970/2003): “Ao se oferecer ao ensino, o discurso psicanalítico leva o psicanalista à posição do psicanalisante, isto é, a não produzir nada que se possa dominar, malgrado a aparência, a não ser a título de sintoma" (p. 310). Embora não seja esse o caso de Althusser, que nesse texto defende a psicanálise enquanto ciência, a ideia do estilo de Lacan como reproduzindo o modo de funcionamento do inconsciente parece autorizar a concepção da psicanálise como uma espécie de discurso mais afeito à associação livre. Não tendo nenhum compromisso com uma teoria clara e ordenada, seria algo mais próximo de uma ficção (Palombini, 1996; Simanke, 2008), mas que estaria ligada a uma transmissão em ato da ética psicanalítica, a partir da utilização do estilo como instrumento de transmissão do saber singular adquiri- 
do na clínica (Juliboni, 2008). A psicanálise não transmitiria uma teoria e sim um estilo (Souza, 1985).

Por mais instigante que essa concepção seja, ela tem recebido uma importante crítica: não há nenhuma necessidade lógica que justifique a idéia de que para falar do inconsciente o discurso deve expressar-se segundo os moldes de funcionamento do próprio inconsciente. Nesse sentido, Beividas afirma: "Estou convencido de que a 'irracionalidade' do inconsciente não implica a construção de uma teoria que não tenha coerência ou racionalidade" (Beividas, 2000, p. 56). Bleichmar e Bleichmar (1992) também protestaram contra a imitação do inconsciente:

O estilo expositivo de Lacan deixa na sombra muitas de suas idéias; argumenta-se que se o inconsciente nunca se exprime diretamente (como demonstra o discurso do paciente ou o texto do sonho), por que não esperar uma formulação análoga por parte de Lacan? Erro crasso: o discurso do cientista deve ser claro e didático, para que possa ser entendido, permitindo que se fixe uma posição diante dele (Bleichmar \& Bleichmar, 1992, p. 177).

Mas seria adequado esperar da psicanálise uma atitude científica para com o seu objeto ou estaria ela liberada de ordenamento lógico, sistematização, confrontação com evidências e racionalidade científica, se aproximando da arte e da poesia? Simanke (2008) vai explorar justamente essa ligação com a poesia, e afirma que a aproximação de Lacan com o movimento surrealista se evidencia inicialmente por uma afinidade de temas em comum: a loucura, o desejo, o feminino e a linguagem. Em seguida, o autor afirma a existência de uma filosofia do surrealismo latente em Lacan, na medida em que há uma recusa do realismo e objetivismo, privilegiando-se o discurso poético como o mais adequado à "apreensão e expressão do real da subjetividade", sendo a "determinação de levar a sério as construções metafóricas às últimas consequências" o ponto nodal de convergência entre Lacan e o surrealismo:

Num certo sentido, poder-se-ia dizer que a psicanálise se transforma, nas mãos de Lacan, num novo gênero literário, concebido para substituir o discurso científico e o discurso filosófico da modernidade sobre o sujeito, que já teriam esgotado seu programa e revelado, historicamente, seus limites. Esse discurso literário - essa forma de "poesia" - teria que ser produzido a partir de um tipo específico de prática, de clínica, de "experimento" (num sentido não de todo alheio aos experimentos e jogos surrealistas), que é a situação analítica com suas regras. Em outras palavras, para Lacan, a psicanálise deveria tornar-se esse tipo de discurso experimental quase literário ou, mais especificamente, quase poético - capaz de apreender, exprimir e, talvez, até mesmo, formalizar uma experiência do sujeito que não pode ser elaborada teoricamente, nem nos termos da objetivação científica, nem no âmbito de uma racionalidade reflexiva (Simanke, 2008, p. 21).

Já para Clément (1983) o estilo de Lacan é em grande parte derivado e inspirado pelas pacientes psicóticas que tanto estudou como psiquiatra no início da carreira, o que o aproxima do delírio:

É uma tênue fronteira, a que separa o trocadilho da invenção poética, a premeditação do incontrolado, a loucura delirante do padrão lacaniano... Desde o início de seu pensamento, Lacan teria experimentado a fascinação do escrito paranóico... Da estranheza incomunicável do estilo delirante fará, mais tarde, uma força calculada... Sim, o primeiro ensinamento da paranóia é o do seu estilo; sob certo aspecto, Lacan retira o estilo paranóico de sua clausura; ele o legaliza, dando-lhe sua carta de nobreza. (p. 44)

$*$

Para sistematizar melhor o que vimos até agora enumeraremos as diferentes interpretações e explicações aqui apresentadas. Consideramos que nenhuma delas está claramente equivocada ou em desacordo com o que sabemos sobre Lacan, ou seja, todas são plausíveis. Em nossa opinião, essas divergências decorrem de modos distintos de pensar a ciência e a própria psicanálise. Seria, portanto, necessário considerar seriamente todas as interpretações aqui compiladas para entender o estilo de Lacan em sua complexidade, sendo muito difícil determinar qual hipótese teria prevalência sobre as demais.

Assim, a dificuldade de Lacan pode ser: 1) uma estratégia para criar uma aura de mistério e enigma, fascinando a plateia (Sokal e Bricmont, 1999); 2) uma evidência de pensamento confuso e mal organizado (atitude descrita, mas não defendida por Fink, 1998); 3) uma falha de estilo, que só prejudica sua compreensão (raciocínio implícito no ideal de ciência e comunicação científica de Sokal e Bricmont, 1999, e presente também em Bleichmar e Bleichmar, 1992); 4) uma característica do ambiente cultural francês da época (Sokal e Bricmont, 1999, Schneiderman, 1988, Merquior, 1991); 5) uma forma de provocar o leitor a ter uma postura mais ativa; seja o discurso de Lacan interpretado como uma imitação do discurso do analisante ou como uma imitação da linguagem do inconsciente, o fundamental dessa concepção é que o estilo 
aparece como uma ferramenta para treinamento e formação de analistas (Glynos e Stavrakakis, 2001, Fink, 1997, Souza, 1985); 6) uma defesa contra a distorção e apropriação indevida do seu pensamento (Fink, 2004, Roudinesco, 2008); 7) uma consequência da opção por um discurso literário em grande parte derivado do surrealismo (Simanke, 2008); 8) fruto da apropriação do estilo encontrado nos delírios de pacientes psicóticos (Clément, 1983).

Dentre os autores que tomam posição, parece-nos oportuno diferenciar pelo menos duas correntes, de posturas diferentes: de um lado, a que discorda do estilo de Lacan e o recrimina, e que tem uma tendência a encarar a psicanálise enquanto ciência, exigindo dela formalização e clareza (exemplificada por Beividas, 2000; Bleichmar \& Bleichmar, 1992; Sokal \& Bricmont, 1999); do outro lado, a corrente que estimula e defende o estilo em questão (muitas vezes inclusive o reproduzindo), e que tem a tendência a encarar a psicanálise como algo indefinido (nem filosofia, nem literatura, nem ciência), às vezes enaltecendo seu caráter subversivo de disciplina inclassificável, sempre às voltas com o impossível, mais próxima da singularidade do sujeito do que da ordenação teórica, e por isso pode justificar uma perspectiva de transmissão subjetiva (exemplificada por Juliboni, 2008; Glynos \& Stavrakakis, 2001; Fink, 1997; Souza, 1985).

A forma de transmissão subjetivista parece ser a dominante dentro do contexto freudo-lacaniano atual: "O elogio do 'estilo individual', em contraposição a uma comunicação científica mais tradicional, a vindicação da psicanálise 'do lado' da enunciação, e não do lado do enunciado científico, a crítica do cogito cartesiano formam hoje um forte consenso" (Beividas, 2000, p. 87). Para Mounin (1972) "No sería ilegítimo encerrar a Lacan en su estilo: caracterizarlo, denfinirlo, psicoanalizarlo, incluso, a partir exclusivamente de su estilo" (p. 207). Se for verdade que há identificação total entre Lacan e seu estilo, então a transmissão subjetiva é a única possível. Se for possível separar estilo e conteúdo, então poderíamos dizer como Schneiderman (1988): "Nada... nos obriga a seguir Lacan no campo do obscuro. Se sua teoria é válida, deve-se ser capaz de articulá-la com clareza e precisão" (p. 7).

Seria o caso de uma escolha ou/ou? Em meio a essa controvérsia, é preciso colocar que não é necessário que a opção entre essas correntes seja mutuamente excludente. Existiria um verdadeiro Lacan a ser reivindicado pela corrente científica ou subjetiva? É possível encontrar embasamento em Lacan inclusive para uma radicalização da postura científica ou da postura subjetiva - a verdade é que se pode utilizar a sua obra para alimentar tanto a uma como a outra concepção: dado o seu caráter multifacetado, resiste ao entendimento e à classificação. Além disso, um texto qualquer pode ter, ao mesmo tempo, um certo grau de participação em um estilo e outro. Mas até mesmo o tamanho da ênfase ou do papel ocupado por um modo e outro de transmissão já é motivo de fortes controvérsias. Considerando o debate dentro desse contexto maior, e considerando também a presença de autores engajados e produtivos em ambos os lados, o mais provável é que essa tensão continue indefinidamente a gerar discussões apaixonadas dentro do campo psicanalítico.

\section{REFERÊNCIAS}

Althusser, L. (1991). Freud e Lacan. Em L. Althusser, Freud $e$ Lacan/Marx e Freud (pp. 47-71) (W. J. Evangelista, Trad.). Rio de Janeiro: Graal. (Original publicado em 1964)

Alves, S. L. (1992). Algumas considerações sobre a proposição de 9 de outubro de 67. Em J. Forbes (Org.), A escola de Lacan: A formação do psicanalista e a transmissão da psicanálise (pp. 73-82). Campinas: Papirus.

Beividas, W. (2000). Inconsciente et verbum: Psicanálise, semiótica, ciência, estrutura. São Paulo: Humanitas.

Bleichmar, N. M., \& Bleichmar C. L. (1992). A psicanálise depois de Freud: Teoria e clínica (F. F. Settineri, Trad.) Porto Alegre: Artes Médicas.

Borch-Jakobsen, M. (1995). Lacan, el amo absoluto (T. P. Lecman, Trad.) Buenos Aires: Amorrortu.

Cabas, A. G. (1982). Curso e discurso da obra de Jacques Lacan. São Paulo: Moraes.

Cesarotto, O., \& Leite, M. P. S. (1993). Jacques Lacan: Uma biografia intelectual. São Paulo: Iluminuras.

Clément, C. (1983). Vidas e lendas de Jacques Lacan (M. C. Kneese, Trad.). São Paulo: Moraes.

Dor, J. (1992). Introdução à leitura de Lacan (C. E. Reis, Trad.). Porto Alegre: Artes Médicas.

Fages, J. B. (1975). Para compreender Lacan (M. D. Magno e G. Lamazière, Trad.). Rio de Janeiro: Rio.

Fink, B. (1997). A clinical introduction to lacanian psychoanalysis: Theory and technique. Cambridge, MA: Harvard University Press.

Fink, B. (1998). O sujeito lacaniano: Entre a linguagem e o gozo (M. L. S. Câmara, Trad.). Rio de Janeiro: Jorge Zahar.

Fink, B. (2004). Lacan to the letter. Minneapolis, MN: University of Minnesota Press.

Glynos, J., \& Stavrakakis, Y. (2001). Posturas e imposturas: O estilo de Lacan e sua utilização da matemática (F. M. Samuda, Trad.). Ágora, 4, 111-130

Hanlon, C., \& Zizek, S. (2001). Psychoanalysis and the postpolitical: An interview with Slavoj Zizek. New Literary History, 32, 1-21. Retirado em 03 de maio de 2009, de http://muse.jhu.edu/login?uri=/journals/new_literary_history 
Juliboni, E. E. C. (2008). O ensino da psicanálise: Estilo e transmissão. Tese de doutorado não-publicada. Universidade Federal do Rio de Janeiro.

Lacan, J. (1998). A instância da letra no inconsciente ou a razão desde Freud. Em J. Lacan, Escritos (pp. 496-533) (V. Ribeiro, Trad.). Rio de Janeiro: Jorge Zahar. (Original publicado em 1957)

Lacan, J. (1998). Abertura desta coletânea. Em J. Lacan, Escritos (pp. 9-11) (V. Ribeiro, Trad.). Rio de Janeiro: Jorge Zahar. (Original publicado em 1966)

Lacan, J. (2003). O ato psicanalítico. Em J. Lacan, Outros escritos (pp. 371-379) (V. Ribeiro, Trad.). Rio de Janeiro: Jorge Zahar. (Original publicado em 1969)

Lacan, J. (2003). Alocução sobre o ensino. Em J. Lacan, Outros escritos (pp. 302-310) (V. Ribeiro, Trad.). Rio de Janeiro: Jorge Zahar. (Original publicado em 1970)

Lacan, J. (2003). Pósfácio ao seminário 11. Em J. Lacan, Outros escritos (pp. 503-507) (V. Ribeiro, Trad.). Rio de Janeiro: Jorge Zahar. (Original publicado em 1973)

Lacan, J. (2006). Lugar, origem e fim do meu ensino. Em J. Lacan, Meu ensino (pp. 9-65) (A. Telles, Trad.). Rio de Janeiro: Jorge Zahar. (Conferência realizada originalmente em 1967)

Mendonça, A. S. (1993). O ensino de Lacan. Rio de Janeiro: Edições do CEL-Gryphus.

Merquior, J. G. (1991). De Praga a Paris: O surgimento, a mudança e a dissolução da ideia estruturalista (A. M. de C. Gibson, Trad.). Rio de Janeiro: Nova Fronteira.

Miller, J.-A. (1997). Lacan elucidado (M. C. F. Kneese e cols., Trad.). Rio de Janeiro: Jorge Zahar.

Mounin, G. (1972). Introducción a la semiologia (C. Manzano, Trad.). Barcelona: Anagrama.
Palombini, A. L. (1996). Fundamentos para uma crítica da epistemologia da psicanálise. Dissertação de mestrado nãopublicada. Universidade Federal do Rio Grande do Sul, Porto Alegre.

Roudinesco, E. (2008). Jacques Lacan: Esboço de uma vida, história de um sistema de pensamento (P. Neves, Trad.). São Paulo: Companhia das Letras.

Schneiderman, S. (1988). Jacques Lacan: A morte de um herói intelectual (D. D. Estrada, Trad.). Rio de Janeiro: Jorge Zahar.

Simanke, R. T. (2008). A ficção como teoria: Revisitando as relações de Lacan com o surrealismo. Estudos Lacanianos, 1. Retirado em 18 de julho de 2010, de http://www.fafich.ufmg. br/estudoslacanianos/pdf/art02_n07_Richard.pdf

Sokal, A., \& Bricmont, J. (1999). Imposturas intelectuais (M. Altman, Trad.). Rio de Janeiro: Record.

Souza, A. M. (1985). Uma leitura introdutória a Lacan (Exegese de um estilo). Porto Alegre: Artes Médicas.

Vallejo, A., \& Magalhães, L. C. (1981). Lacan: Operadores da leitura. São Paulo: Perspectiva.

Webster, R. (2002).The cult of Lacan: Freud, Lacan and the mirror stage. Retirado em 03 de abril de 2010, de http://www.richardwebster.net/thecultoflacan.html

Zizek, S. (2007). How to read Lacan. Retirado em 06 de agosto de 2008, de http://www.lacan.com/zizhowto.html

Recebido: $24 / 02 / 2011$

Última revisão: 02/08/2011

Aceito: 02/08/2011

\section{Notas:}

1 Uma busca por "Lacan” no campo de assunto do Banco de Teses da CAPES nos revelou 1.032 resultados em 25/11/2010.

2 Sobre o assunto da incompreensão de Lacan por parte da inteligência francesa da época, ver também Roudinesco (2008, p. 288).

3 Tradução nossa.

4 Idem.

5 Sobre o caráter de seita da escola lacaniana, ler a seção "El hechicero y su magia" no capítulo 5 de Borch-Jacobsen (1995), e também o bom artigo de Webster (2002).

6 Aproveitei aqui a tradução para o português que se encontra no artigo de Glynos e Stavrakakis (2001), que também citam esse trecho.

7 Tradução nossa.

8 Uma nota de Alves (1992, p. 75) indica que ele toma essa ideia de Jacques-Alain Miller. 